LBL-37083

UC-414

\title{
Thick Amorphous Silicon Layers Suitable for the Realization of Radiation Detectors
}

Wan-Shick Hong, Vesselinka Petrova-Koch ${ }^{*}$, John S. Drewery, Tao Jing, Hyong-Koo Lee and Victor Perez-Mendez

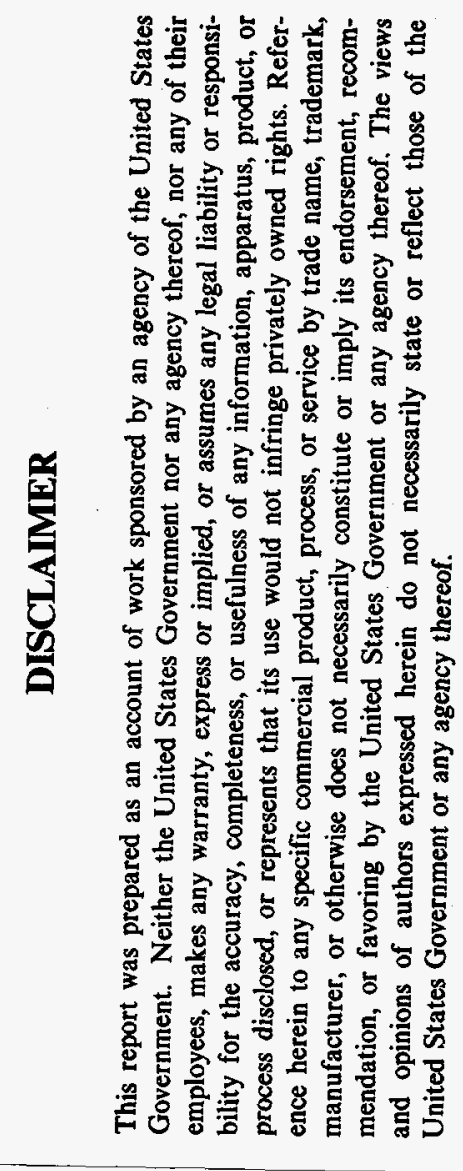

\author{
Physics Division \\ Lawrence Berkeley Laboratory \\ University of California \\ Berkeley, CA 94720, U.S.A. \\ *Technische Universität Munich \\ 85747 Garching, Germany
}

April 1995

This work was supported by the Director, Office of Energy Research, Office of High Energy and Nuclear Physics, Division of High Energy Physics of the U.S.Department of Energy under Contract No.DE-AC03-76SF00098 


\section{DISCLAIMER}

Portions of this document may be illegible in electronic image products. Images are produced from the best available original document. 


\section{THICK AMORPHOUS SILICON LAYERS SUITABLE FOR THE REALIZATION OF RADIATION DETECTORS}

W.S.Hong. V.Petrova-Koch*, J.Drewery, T.Jing, H.Lee and V.Perez-Mendez Physics Division, Lawrence Berkeley Laboratory, Berkeley, CA 94720, U.S.A., *Technische Universität Munich, 85747 Garching, Germany

\section{ABSTRACT}

Thick silicon films with good electronic quality have been prepared by glow discharge of He-diluted $\mathrm{SiH}_{4}$ at a substrate temperature $\sim 150^{\circ} \mathrm{C}$ and subsequent annealing at $160^{\circ} \mathrm{C}$ for about 100 hours. The stress in the films obtained this way decreased to $\sim 100 \mathrm{MPa}$ compared to the 350 $\mathrm{MPa}$ in conventional a-Si:H. The post-annealing helped to reduce the ionized dangling bond density from $2.5 \times 10^{15} \mathrm{~cm}^{-3}$ to $7 \times 10^{14} \mathrm{~cm}^{-3}$ without changing the internal stress. IR spectroscopy and hydrogen effusion measurements implied the existence of microvoids and tiny crystallites in the material showing satisfactory electronic properties. P-I-N diodes for radiation detection applications have been realized out of the new material.

\section{INTRODUCTION}

Thick $(\sim 50 \mu \mathrm{m})$ hydrogenated amorphous silicon (a-Si:H) films have been drawing attention because of their potential advantages for the realization of large area charged particle detectors.[1, 2, 3] The deposition of thick, high quality layers by the established a-Si:H technology (glow-discharge of $\mathrm{SiH}_{4}$ at $\mathrm{T}_{\mathrm{S}} \approx 250^{\circ} \mathrm{C}$ ) is handicapped by the high residual stress of such films, which causes substrate bending or film spallation.[4, 5, 6] However, the electronic quality of the low stressed material was reported to be poor. $[7,8]$. Optimization of the deposition conditions and introduction of post-deposition steps helped us to overcome some of the difficulties. Our goal was to prepare films having: i) a high deposition rate, ii) residual stress, $\sigma \sim$ $100 \mathrm{MPa}$ or less, iii) an ionized dangling bond density $\mathrm{N}_{\mathrm{d}}{ }^{*} \sim 5 \times 10^{14} \mathrm{~cm}^{-3}$ or less and iv) mobility-lifetime product $\mu \tau$ of charge carriers of the order of $10^{-8} \sim 10^{-7} \mathrm{~cm}^{2} / \mathrm{V}$.

The following knowledge from the literature was a helpful guide to us on the way to overcome the above mentioned difficulties. The deposition rate was shown to increase when silane 
is diluted with inert gas. $[9,10,11]$ However, in many cases, adding inert gas to the plasma resulted in columnar morphology which degrades the transport characteristics.[12,13] Among the various inert gases, helium was found empirically to have a minimal deterioration effect on the film quality. $[14,15]$ Therefore, we chose $\mathrm{He}$ as the dilution gas.

Lowering the substrate temperature was known to reduce the residual stress in films from values as high as $350 \mathrm{MPa}$ down to $100 \mathrm{MPa}$ or even smaller.[3, 16] It was found that during such process a void-rich structure formed, which is capable of releasing the stress.[17] The asdeposited void-rich material, however, has poor electronic quality.[18] On the other hand, we have shown recently that annealing at temperatures lower than the deposition temperature can reduce the density of dangling bonds while the stress remains unchanged.[19]

In this paper we describe how we fabricated thick a-Si:H films with low residual stress and satisfactory electronic properties. We also present data revealing the structural changes appearing in the films under the new preparation condition.

\section{EXPERIMENTAL PROCEDURES}

Intrinsic layers with thicknesses of $5 \sim 50 \mu \mathrm{m}$ were prepared by the plasma enhanced chemical vapor deposition (PECVD) technique at an excitation frequency of $85 \mathrm{MHz}$ from a gas mixture of $40 \% \mathrm{SiH}_{4}-60 \% \mathrm{He}$. The same gas mixture was also used for making thin $\mathrm{p}$ - and $\mathrm{n}$ doped layers for fabrication of $\mathrm{p}-\mathrm{i}-\mathrm{n}$ diodes. Corning 7059 glass coated with thin $(<200 \AA)$ indium tin oxide layer was used as a substrate. The substrate temperature was varied between $130^{\circ} \mathrm{C}$ and $250^{\circ} \mathrm{C}$ while all the other parameters were kept constant. Samples from pure silane were also deposited for comparison. Table I summarizes the deposition conditions for He-diluted and undiluted layers. Annealing at $160^{\circ} \mathrm{C}$ for 100 hours was applied to all samples.

Table I Deposition Parameters for Conventional and He-diluted Si films.

\begin{tabular}{|c|c|c|c|c|}
\hline Gas & Temp. $\left({ }^{\circ} \mathrm{C}\right)$ & $\begin{array}{c}\text { Power } \\
\text { Density } \\
\left(\mathrm{mW} / \mathrm{cm}^{2}\right)\end{array}$ & $\begin{array}{c}\text { Pressure } \\
(\mathrm{mTor})\end{array}$ & $\begin{array}{c}\text { Deposition } \\
\text { Rate } \\
(\mu \mathrm{m} / \mathrm{hr} .)\end{array}$ \\
\hline $100 \% \mathrm{SiH}_{4}$ & $\begin{array}{c}150,160,170, \\
190,250\end{array}$ & 40 & 300 & 2.3 \\
\hline $40 \% \mathrm{SiH}_{4}-60 \% \mathrm{He}$ & $\begin{array}{c}130,150,160, \\
170,190,250\end{array}$ & 90 & 500 & $3.5 \sim 4$ \\
\hline
\end{tabular}




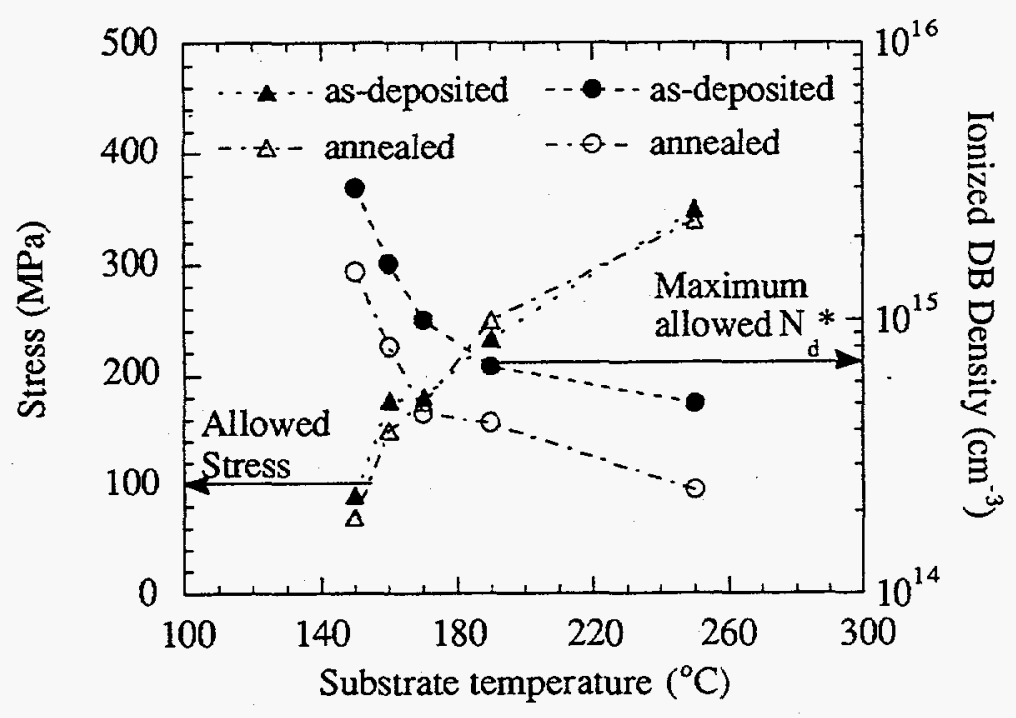

Fig. 1 Change in ionized dangling bond density $\left(\mathrm{N}_{\mathrm{d}}{ }^{*}\right)$ and residual stress with deposition temperature for standard samples. Closed and open symbols represent as-deposited and annealed samples, respectively.
The residual stress was determined by scanning the backside of the substrate with an Alphastep 200 profilometer and inserting the curvature in Stoney's equation.[20] The ionized dangling bond density, $\mathrm{N}_{\mathrm{d}}{ }^{*}$, before and after annealing, was measured by the hole onset technique described elsewhere. [21] The electron mobility, $\mu_{\mathrm{e}}$, and mobility lifetime product, $(\mu \tau)_{e}$, were measured by the standard time of flight technique.[22] The vibrational spectra were detected by a FTIR Perkin-Elmer spectrometer in the range of $250-4500 \mathrm{~cm}^{-1}$ at a resolution of $4 \mathrm{~cm}^{-1}$. The hydrogen desorption was measured with a home-made set up at a constant heating rate of $20^{\circ} \mathrm{K} / \mathrm{min}$. in the range between room temperature and $900^{\circ} \mathrm{C}$.

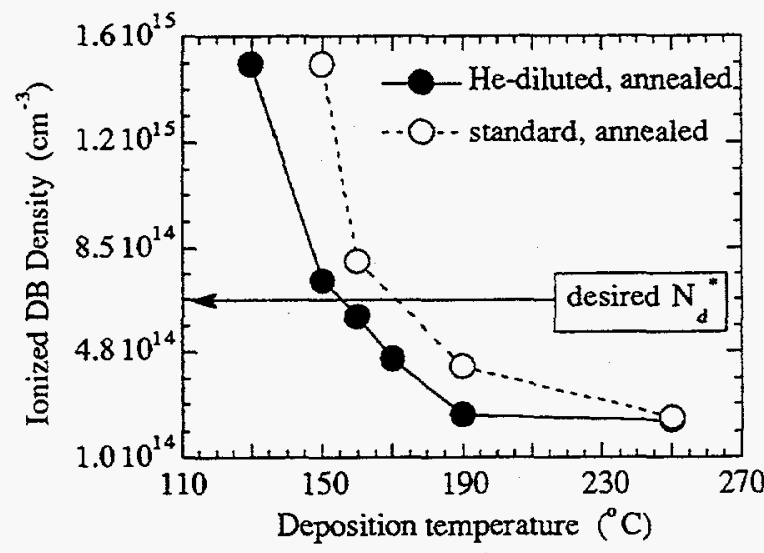

(a)

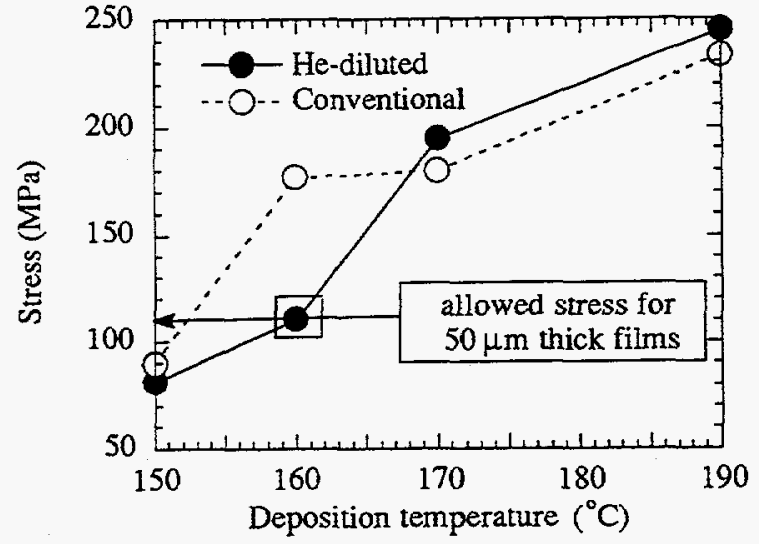

(b)

Fig. 2 (a) Change in ionized dangling bond density with deposition temperature for annealed samples, (b) Change in residual stress with deposition temperature 


\section{OPTIMIZATION OF THE DEPOSITION CONDITIONS}

In Fig. 1 results are summarized[23] to show the effects of substrate temperature and postannealing on the stress, $\sigma$, and the ionized dangling bond density, $\mathrm{N}_{\mathrm{d}}{ }^{*}$ for samples prepared from pure $\mathrm{SiH}_{4}$. One observes clearly pronounced anti-correlation between the stress and the $\mathrm{N}_{d}{ }^{*}$. From this figure we also see that the post-annealing step affects significantly the $\mathrm{N}_{\mathrm{d}}{ }^{*}$ while the stress remains unchanged. Both the $\mathrm{N}_{\mathrm{d}}{ }^{*}$ and the stress experience strong gradients at substrate temperatures between $150^{\circ} \mathrm{C}$ and $200^{\circ} \mathrm{C}$. In the same figure the desired values of the $\mathrm{N}_{\mathrm{d}}{ }^{*}$ and the stress for detector application are given by arrows. For the as-prepared samples it becomes clear from the figure that no deposition temperature provides films satisfying $\sigma$ and $N_{d}{ }^{*}$ at the same time. Annealing improves the situation significantly, but at the cross-over point around $160^{\circ} \mathrm{C}$ the stress value is still higher than the desired value. For He-diluted samples a similar anti-correlation between $\sigma$ and $N_{d}{ }^{*}$ is observed. The annealed and He-diluted samples show further quantitative improvement. This is demonstrated in Fig. 2.

In Fig. 2a the $\mathrm{N}_{\mathrm{d}}{ }^{*}$ vs. deposition temperature for He-diluted and conventional samples are compared. It is seen that with He-dilution the ionized dangling bond density is further reduced. Also the stress in the He-diluted samples is lower than in the conventional materials at $\sim 160^{\circ} \mathrm{C}$, as demonstrated in Fig. $2 b$.

Table II. Measured Electron Transport Parameters and Stress

\begin{tabular}{|c|c|c|c|c|}
\hline Samples & $\begin{array}{c}\mu_{\mathrm{e}} \\
\left(\mathrm{cm}^{2} / \mathrm{V} \cdot \mathrm{s}\right) \\
\end{array}$ & $\begin{array}{c}(\mu \tau)_{\mathrm{e}} \\
\left(\mathrm{cm}^{2} / \mathrm{V}\right)\end{array}$ & $\mathrm{N}_{\mathrm{d}}^{*}\left(\mathrm{~cm}^{-3}\right)$ & Stress (MPa) \\
\hline \multicolumn{5}{|c|}{ Standard (deposited at $250^{\circ} \mathrm{C}$ ) } \\
\hline as-deposited & 1.2 & $1.2 \times 10^{-7}$ & $6 \times 10^{14}$ & 350 \\
\hline annealed & 1.2 & & $3 \times 10^{14}$ & 330 \\
\hline \multicolumn{5}{|c|}{ Standard (deposited at $150^{\circ} \mathrm{C}$ ) } \\
\hline as deposited & 0.5 & $3 \times 10^{-9}$ & $2.5 \times 10^{15}$ & 90 \\
\hline annealed & 0.5 & $7 \times 10^{-9}$ & $1.5 \times 10^{15}$ & 70 \\
\hline \multicolumn{5}{|c|}{ He-diluted(deposited at $250^{\circ} \mathrm{C}$ ) } \\
\hline as-deposited & 1.2 & $3 \times 10^{-8}$ & $3 \times 10^{14}$ & 320 \\
\hline annealed & 1.2 & & $3 \times 10^{14}$ & 310 \\
\hline \multicolumn{5}{|c|}{ He-diluted(deposited at $150^{\circ} \mathrm{C}$ ) } \\
\hline as-deposited & 0.8 & $1 \times 10^{-8}$ & $3 \times 10^{15}$ & 70 \\
\hline annealed & 0.8 & $2 \times 10^{-8}$ & $7 \times 10^{14}$ & 80 \\
\hline
\end{tabular}


In Table II the results of all four important electronic parameters for samples prepared at $250^{\circ} \mathrm{C}$ and $160^{\circ} \mathrm{C}$ with and without He-dilution, before and after annealing, are listed. Only the material prepared with He-dilution at $150^{\circ} \mathrm{C}$ and post-annealed for 100 hours provides a satisfying quality for realization of particle detectors.

\section{STRUCTURAL DIFFERENCES BETWEEN THE CONVENTIONAL a-Si:H AND THE NEW FILMS}

In Fig. 3 a typical FTIR transmittance spectrum of varous films is depicted. In addition to the stretching (s) band around $2000 \mathrm{~cm}^{-1}$ and the rocking (r) band at $\sim 660 \mathrm{~cm}^{-1}$ which have been reported for high quality a-Si:H,[24] one clearly sees a doublet of modes around $850 \mathrm{~cm}^{-1}$ which correspond to the $\mathrm{Si}-\mathrm{H}_{2}$ and $\mathrm{Si}-\mathrm{H}_{3}$ bending (b) and wagging (w) region. Also, there is an additional band at $\sim 500 \mathrm{~cm}^{-1}$, which we assign to $\mathrm{H}$-induced $\mathrm{Si}$-Si vibrations. To the best of our knowledge, the latter has not been reported previously in the literature.

Fig. 4 shows an expanded plot of the $\mathrm{Si}-\mathrm{H}_{\mathrm{X}}$ stretching (fig.4a), $\mathrm{Si}-\mathrm{H}_{\mathrm{x}}$ bending (fig.4b) and the Si-Si:H (fig.4c) regions. Fig. 4a allows us to resolve the two peaks in the stretching region.

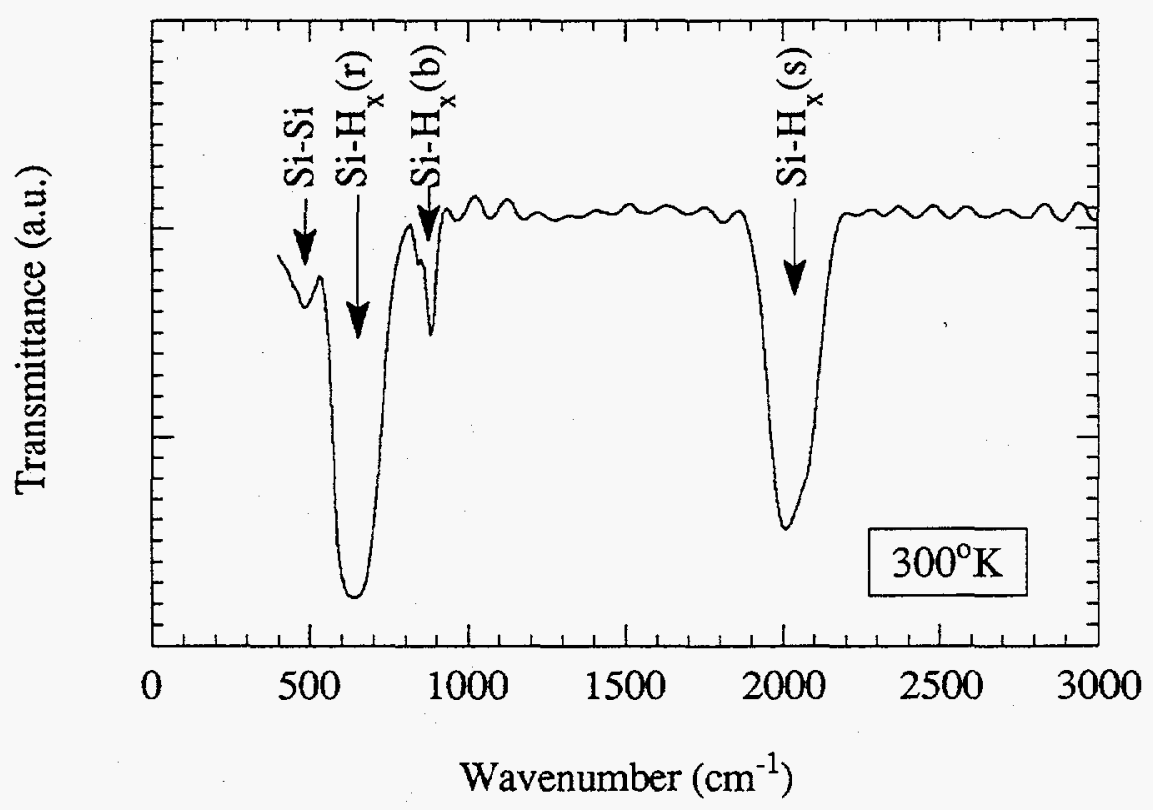

Fig. 3 FTIR transmittance spectrum of the He-diluted, low-temperature $\left(150^{\circ} \mathrm{C}\right)$ deposited and post-annealed sample. 


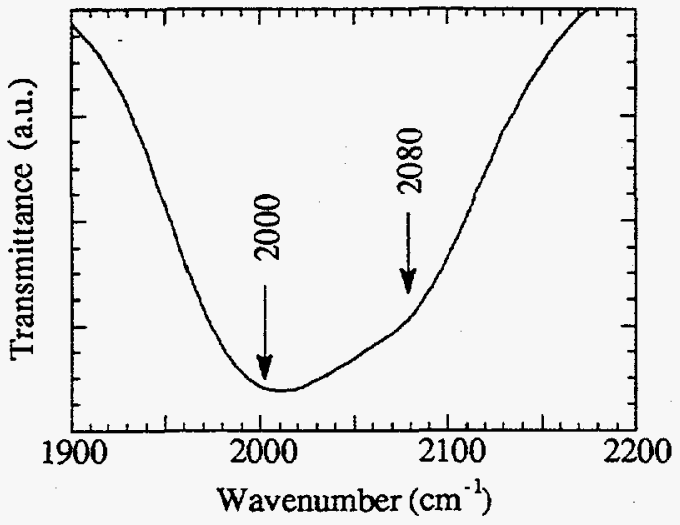

(a)

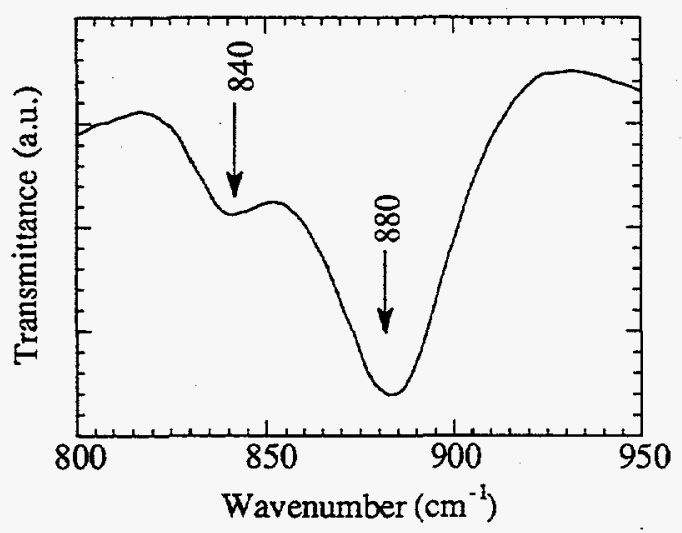

(b)

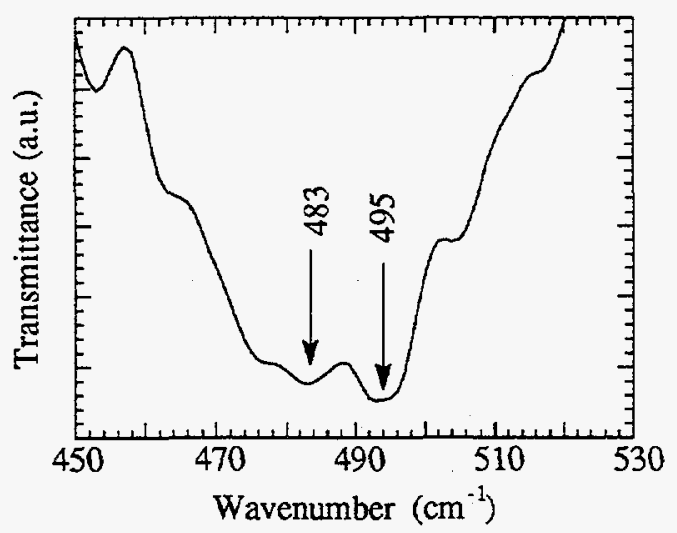

(c)

Fig. 4 Expanded FTIR spectra for the (a) stretching, (b) bending, and (c) Si-Si vibration region
The first broad peak around $2000 \mathrm{~cm}^{-}$ 1 is known to be due to vibration of the $\mathrm{Si}-\mathrm{H}_{1}$ bond in the interior of the amorphous network. The second one is shifted to higher wavenumber by $-80 \mathrm{~cm}^{-1}$. Such shift is typical for the $\mathrm{SiH}_{\mathrm{x}}$ vibration on the $\mathrm{Si}$ surface, as known from study of $\mathrm{H}$ terminated c-Si monosurfaces.[25]. The appearance of this mode is a proof for the existence of voids in our materials. This is in agreement with the observation reported previously in the literature on lowtemperature deposited a-Si:H films. The appearance of the scissor mode around 880 $\mathrm{cm}^{-1}$ in fig. $4 \mathrm{~b}$ provides the information that our film contains a non-negligible amount of $\mathrm{Si}-\mathrm{H}_{2}$ bonds. The peak at $840 \mathrm{~cm}^{-1}$ is due to the existence of short $\left(\mathrm{Si}-\mathrm{H}_{2}\right)_{\mathrm{n}}$ chains in the network on the void surfaces. The appearance of the mode at $500 \mathrm{~cm}^{-1}$ is a characteristic for the new films which we do not observe in the conventional a-Si:H. This spectrum is different from the typical Raman spectra reported for a-Si:H. There is a pronounced shoulder of this band in the region higher than $-500 \mathrm{~cm}^{-1}$, which can be caused by the existence of tiny crystalline inclusion, covered by $\mathrm{H}$, in the film. In this case the $\mathrm{Si}-\mathrm{Si}$ transverse optical (TO) vibration can be induced by $\mathrm{H}$ and becomes observable in the IR-spectrum.

In Fig. 5, we show a typical hydrogen-effusion spectrum for the new samples. For comparison, also an effusion spectrum of conventional a-Si:H is shown. The high thermal stability of the He-diluted 


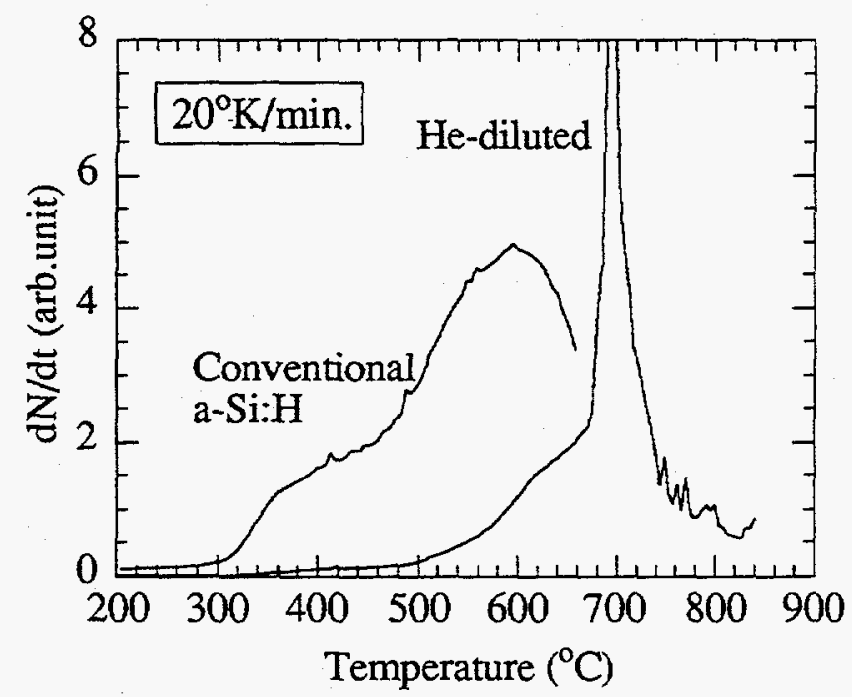

Fig. 5 Hydrogen effusion spectra of the conventional a-Si:H and of the He-diluted and low-temperature deposited sample. material seen by a strong $\mathrm{H}$-evolution peak at $\sim 700^{\circ} \mathrm{C}$ is surprising. Usually, one expects the $\mathrm{Si}-\mathrm{H}_{2}$ bonds to decompose at $\sim 400^{\circ} \mathrm{C}[26]$ More experiments need to be done to understand the unusual $\mathrm{H}$ desorption kinetics in this material.

\section{CONCLUSION}

We have been able to obtain a moderate increase in the growth rate to $3.5 \sim 4 \mu \mathrm{m} / \mathrm{hr}$. and residual stress as

low as $\sim 100 \mathrm{MPa}$ for films deposited at $150^{\circ} \mathrm{C}$ with $\mathrm{He}$-dilution. Post-annealing at $160^{\circ} \mathrm{C}$ for 100 hours led to sufficiently low $\mathrm{N}_{\mathrm{d}}{ }^{*}\left(\sim 7 \times 10^{14} \mathrm{~cm}^{-3}\right)$. The combination of the low temperature growth, He-dilution and post-annealing of the film lends a way to produce a material that has a low residual stress and electrical properties satisfactory for thick $(\sim 50 \mu \mathrm{m})$ radiation detectors. The structure of the new film is seen to contain voids and tiny crystalline inclusions and is different from the one observed in conventional a-Si:H. A void-rich material is created here with satisfactory electronic quality, which is in contrast with previous conclusions in the literature. The high temperature stability of the hydrogen bonds remains an unresolved phenomenon.

\section{ACKNOWLEDGMENT}

This work was supported by the Director, Office of Energy Research of the U.S.Department of Energy under Contract No. DE-AC03-76SF00098

\section{REFERENCES}

[1] J.Xi, R.E.Hollingsworth, R.H.Buitrago, D.Oakley, J.P.Cumalat, U.Nauenberg, J.A.McNeil, D.F.Anderson and V.Perez-Mendez, Nucl. Instr. Meth., A301 219 (1991)

[2] V.Perez-Mendez, G.Cho, J.Drewery, T.Jing, S.N.Kaplan, S.Qureshi, D.Wildermuth, C.Goodman, I.Fujieda and R.A.Street, Nucl. Phys., B 32287 (1993) 
[3] W.S.Hong, A.Mireshghi, J.S.Drewery, T.Jing, S.N.Kaplan, Y.Kitsuno, H.Lee and V.Perez-Mendez, to be published in the IEEE Trans. Nucl. Sci., August (1995)]

[4] K.Tamahashi, M.Wakagi, F.Ishikawa, T.Kaneko, K.Tamura, A.Satoh and M.Hanazono, Mat. Res. Soc. Symp. Proc., 192621 (1990)

[5] H.Kakinuma, S.Nishikawa, T.Watanabe and K.Nihei, J. Appl. Phys., 593110 (1986)

[6] A.Matsuda, T.Kaga, H.Tanaka and K.Tanaka, Jap. J. Appl. Phys., 23 L567 (1984)

[7] W.E.Spear and M.Heintze, Phil. Mag. B 54343 (1986)

[8] W.S.Hong, J.C.Delgado, O.Ruiz and V.Perez-Mendez, Presented at the MRS Symp., Boston, MA, Nov.28-Dec.2, 1994, and to be published in the Proceedings

[9] M.Heintze, R.Zedlitz and G.H.Bauer, Mat. Res. Soc. Symp. Proc., 29749 (1993)

[10] J.A.Thornton and D.W.Hoffman, J. Vac. Sci.Tech., 18203 (1981)

[11] U.Kroll, F.Finger, J.Dutta, H.Keppner, A.Shah, A.Howling, J.-L.Dorier and Ch.Hollenstein, Mat. Res. Soc. Symp. Proc., 258135 (1992)

[12] J.Kakalios, R.A.Street, C.C.Tsai, and R.Weisfield, Mat. Res. Soc. Symp. Proc., 95243 (1987)

[13] J.C.Knights and R.A.Lujan, Appl. Phys. Lett., 35244 (1979)

[14] J.C.Knights, R.A.Lujan, M.P.Rosenblum, R.A.Street, D.K.Biegelsen and J.A.Reimer, Appl. Phys. Lett., $38 \underline{5} 331$ (1981)

[15] Y.Ohashi, J.Kenne, M.Konagai and K.Takahashi, Appl. Phys. Lett., 421028 (1983)

[16] P.Chabloz, H.Keppner, V.Baertschi, A.Shah, D.Chatellard, J.-P.Egger, M.Denoreaz, E.Jeannet, J.-F.Germond, R.Vuilleumier, Mat. Res. Soc. Symp. Proc., 2581057 (1992)

[17] Y.Hishikawa, J.Appl.Phys., 623150 (1987)

[18] Y.Ziegler, H.Curtins, J.Baumann and A.Shah, Mat. Res. Soc. Symp. Proc., 14981 (1989)

[19] Y.Kitsuno, G.Cho, J.Drewery, W.S.Hong and V.Perez-mendez, Jap. J. Appl. Phys., 33 Part 13A 1261 (1994)

[20] A.Brenner and S.Senderoff, J. Res. Nat'l. Bureau of Stanards, 42105 (1949)

[21] S.Qureshi, V.Perez-Mendez, G.Cho, I.Fujieda, and R.A.Street, IEEE Trans. Nucl. Sci., NS-36 194 (1989)

[22] W.E.Spear, J. Non-Cryst. Sol., 1197 (1968)

[23] W.S.Hong, J.S.Drewery, T.Jing, H.Lee, S.N.Kaplan and V.Perez-Mendez, submitted to Section A of Nucl. Inst. Meth. in Phys. Res.

[24] P.J.Zanzuchi, Semiconductors and Semimetals, Vol.21 Part B, Ed. by J.Pankove, pp.113, Academic Press (1984)

[25] N.M.Johnson, F.A.Ponce, R.A.Street and R.J.Nemanich, Phys. Rev. B, 354166 (1987)

[26] W.Beyer, H.Wagner and H.Mell, Solid State Commun., 39375 (1981) 